\title{
Variations in T cell transcription factor gene structure and expression associated with the two disease forms of sheep paratuberculosis
}

\author{
Louise Nicol ${ }^{1}$, Hazel Wilkie ${ }^{1}$, Anton Gossner ${ }^{1}$, Craig Watkins ${ }^{2}$, Robert Dalziel ${ }^{1}$ and John Hopkins ${ }^{1 *}$
}

\begin{abstract}
Two different forms of clinical paratuberculosis in sheep are recognised, related to the level of bacterial colonization. Paucibacillary lesions are largely composed of lymphocytes with few bacteria, and multibacillary pathology is characterized by heavily-infected macrophages. Analysis of cytokine transcripts has shown that inflammatory Th1/ Th17T cells are associated with development of paucibacillary pathology and Th2 cytokines are correlated with multibacillary disease. The master regulator T cell transcription factors TBX21, GATA3, RORC2 and RORA are critical for the development of these T cell subsets. Sequence variations of the transcription factors have also been implicated in the distinct disease forms of human mycobacterial and gastrointestinal inflammatory diseases. Relative RT-qPCR was used to compare expression levels of each transcript variant of the master regulators in the ileo-caecal lymph nodes of uninfected controls and sheep with defined paucibacillary and multibacillary pathology. Low levels of GATA3 in multibacillary sheep failed to confirm that multibacillary paratuberculosis is caused simply by a Th2 immune response. However, high levels of TBX21, RORC2 and RORC2v1 highlights the role of Th1 and Th17 activation in paucibacillary disease. Increased RORAv1 levels in paucibacillary tissue suggests a role for RORa in Th17 development in sheep; while elevated levels of RORAv4 hints that this variant might inhibit RORa function and depress Th17 development in multibacillary sheep.
\end{abstract}

\section{Introduction}

Paratuberculosis (Johne's disease) is a common intestinal disease of ruminants caused by infection with the intracellular bacterium Mycobacterium avium subspecies paratuberculosis (Map) [1]. As with tuberculosis [2], clinical disease only develops in a minority of infected individuals, and in sheep the disease can be one of two forms. About $70 \%$ of the diseased animals develop multibacillary or lepromatous pathology with lesions in the terminal ileum composed of heavily infected macrophages [3, 4], and the remainder develop paucibacillary or tuberculoid

\footnotetext{
*Correspondence: john.hopkins@ed.ac.uk

${ }^{1}$ The Roslin Institute \& R(D)SVS, University of Edinburgh, Easter Bush, Midlothian EH25 9RG, UK

Full list of author information is available at the end of the article
}

pathology with characteristic lymphocytic infiltration, granulomatous inflammation and few bacteria.

The immunology of paratuberculosis in sheep is also similar to that of the tuberculoid and lepromatous forms of tuberculosis and leprosy $[5,6]$. Multibacillary pathology is linked with a strong Th2 response with high levels of interleukin (IL)-5 [7, 8] and paucibacillary disease is associated with an inflammatory Th1/Th17 response, characterized by IL-12, IL-17A and IFN $\gamma[7,9,10]$. However, the immune response associated with the two forms of the disease is not a simple matter of Th1/Th2 discrimination as there seems to be a total $\mathrm{T}$ cell dysfunction and loss of homeostasis in animals with multibacillary pathology [11-13], possibly concerned with changes to co-stimulatory and second messenger expression [14, 15].

In common with tuberculosis and leprosy, the epidemiology of paratuberculosis strongly suggests a genetic 
susceptibility to disease severity and pathological form $[16,17]$. Many of the genes associated with severity of human mycobacterial diseases and pathology belong to the pathways that control differential $\mathrm{T}$ cell activation [16]. The polarization of $\mathrm{T}$ cells into the various $\mathrm{CD} 4+\mathrm{T}$ cell functional subsets occurs within organized lymphoid tissue and is largely controlled by the master regulator transcription factors that control differential cytokine production including Tbx21 or T-bet (TBX21), GATA-3 (GATA3), RORyt (RORC2) and ROR $\alpha$ (RORA); [18]. Tbx21 and GATA- 3 are the regulators of Th1 and Th2 differentiation respectively; initially by transactivation of relevant cytokine genes and also by reciprocal repression $[19,20]$. ROR $\gamma t$ is the major transcription factor that regulates Th17 development, and ROR $\alpha$ is required for the maximum production of the cytokine IL-17A [21]. GATA-3 and ROR $\alpha$ are also important in the development and function of the different subsets of innate lymphoid cells 2 (ILC2), cells associated with mucosal surfaces in mice and important in the initiation of Th2 responses [22].

Map is also implicated in the pathogenesis of Crohn's disease [14], and these master regulators play important roles in the pathogenesis of this disease and other inflammatory diseases at mucosal sites. Tbx21 expression is implicated in the abnormal expression of IFN $\gamma$ in Crohn's disease and GATA-3 is involved in the immunopathology of ulcerative colitis $[23,24]$. Th17 cells function largely in the development of inflammatory reactions and several inflammatory conditions are linked with ectopic Th17 $\mathrm{T}$ cell activation; therefore ROR $\gamma \mathrm{t}$ and ROR $\alpha$ are also implicated in inflammatory disease $[25,26]$. Alternative splicing of exons (or part of an exon or intron) into a transcript introduces variations into many genes [27] and such variations in the transcripts of the human master regulator transcription factors can modify their functions [28-30].

We have recently identified two transcript variants of both sheep GATA3 and RORC2, a single TBX21 transcript and five variants of $R O R A$ [31]. In this study we compared the expression of each transcript variant of these four transcription factors, in the ileo-caecal lymph nodes (ICLN) that drain the disease lesions in the terminal ileum adjacent to the ileo-caecal valve, in sheep with define multibacillary or paucibacillary pathology, to test the hypothesis that the pathological form of sheep paratuberculosis is associated with differential expression of individual $\mathrm{T}$ cell transcription factor variants.

\section{Materials and methods}

\section{Animals, disease diagnosis and tissue collection}

Animals with clinical disease were outbred female Blackface or Blackface $x$ sheep with naturally-acquired MAP infection (Table 1) from six farms; healthy, uninfected control sheep were all Blackface ewes from a single farm with no history of paratuberculosis. Paratuberculosis pathology in each animal was confirmed at post-mortem by haematoxylin and eosin and Ziehl-Neelsen histopathology of the terminal ileum lesions and mesenteric lymph nodes [7]. PCR for insertion sequence 900 (IS900) was used to confirm infection. There were six animals in each of three groups; multibacillary $(M)$, paucibacillary (P) and uninfected controls (C). Tissue was ICLN removed at post-mortem, cut into blocks of $\sim 0.5 \mathrm{~g}$ and placed in five volumes of RNAlater (Ambion, UK), then incubated overnight at $4{ }^{\circ} \mathrm{C}$ and stored at $-80{ }^{\circ} \mathrm{C}$. No animals were euthanized specifically for this study; infected sheep were humanely culled for clinical reasons and uninfected controls were euthanized for reasons unrelated to this study (uninfected controls).

\section{Is 900 pcr}

ICLN was tested for MAP infection by PCR for IS900. Two independent primer sets were used [32, 33]; set 1 (for: GTTCGGGGCCGTCGCTTAGG; rev: GC GGGCGGCCAATCTCCTT) and set 2 (for: CTG GCTACCAAACTCCCGA; rev: GAACTCAGCGCCCA GGAT) generated products of $99 \mathrm{bp}$ and $314 \mathrm{bp}$ respectively. Genomic DNA (gDNA) was purified using the Wizard $^{\circledR}$ Genomic DNA Purification Kit (Promega, UK). All reactions used FastStart Taq DNA Polymerase (Roche Diagnostics, UK) following the manufacturer's instructions, with $500 \mathrm{ng}$ of gDNA and $0.2 \mu \mathrm{M}$ of each primer. PCRs used a Veriti ${ }^{\circledR}$ Thermal Cycler (Applied Biosystems, UK) with four reactions performed for each primer set at four different annealing temperatures. PCR parameters were: $5 \mathrm{~min}$ at $95{ }^{\circ} \mathrm{C}$, then 35 cycles of $15 \mathrm{~s}$ at $95{ }^{\circ} \mathrm{C}, 15 \mathrm{~s}$ at $55{ }^{\circ} \mathrm{C}, 58{ }^{\circ} \mathrm{C}, 60{ }^{\circ} \mathrm{C}$, or $62{ }^{\circ} \mathrm{C}$, and $30 \mathrm{~s}$ at $72{ }^{\circ} \mathrm{C}$, with final elongation of $10 \mathrm{~min}$ at $72{ }^{\circ} \mathrm{C}$. PCR products were separated by $2 \%$ agarose gel electrophoresis, purified with a MinElute Gel Extraction Kit (Qiagen, UK); cloned using a TOPO TA cloning kit (Invitrogen, UK) and sequenced using the BigDye Terminator v3.1 Cycle Sequencing Kit and 3730 DNA Analyser (Applied Biosystems). The presence of an amplicon, confirmed by sequencing, from either primer set was taken as a positive indication for the presence of MAP; the absence of an amplicon in all PCR reactions was confirmation of absence of MAP infection.

\section{Quantitative real-time RT-PCR analysis}

Total RNA was obtained from $\sim 20 \mathrm{mg}$ tissue using the Ribopure Kit (Ambion, UK) according to the manufacturer's instructions, DNA was removed by On-column PureLink ${ }^{\circledR}$ DNase I treatment (Ambion). RNA quantity, quality and integrity were determined by NanoDrop 
Table 1 Details of paratuberculosis-diseased and control sheep

\begin{tabular}{|c|c|c|c|c|c|c|c|}
\hline Sheep ID & Breed & Origin $^{a}$ & Age (years) & $S G I^{b}$ & $\mathrm{AFB}^{\mathrm{C}}$ & $I S 900^{\mathrm{d}}$ & Diagnosis $^{\mathrm{e}}$ \\
\hline SH.139 & Blackface & A & 3 & 5 & 4 &,++ & M \\
\hline SH.140 & Blackface & A & 3 & 7 & 4 &,++ & M \\
\hline SH.146 & Blackface $x$ & B & 2.5 & 5 & 4 &,++ & M \\
\hline SH.190 & Blackface & C & 3 & 5 & 4 &,++ & M \\
\hline SH.199 & Blackface & $C$ & 2 & 6 & 4 &,++ & M \\
\hline SH.204 & Blackface & $D$ & 1.5 & 6 & 4 &,++ & M \\
\hline SH.107 & Blackface $x$ & E & 2.5 & 2.5 & 0 &,++ & $P$ \\
\hline SH.147 & Blackface $x$ & B & 2 & 3 & 0 &,++ & $P$ \\
\hline SH.155 & Blackface & $\mathrm{F}$ & 3 & 2 & 0 &,++ & $P$ \\
\hline SH.160 & Blackface $x$ & B & 3 & 2.5 & 0 &,++ & $P$ \\
\hline SH.188 & Blackface $x$ & B & 4 & 4 & 1 &,++ & $P$ \\
\hline SH.205 & Blackface & $D$ & 4 & 2 & 0 &,++ & $P$ \\
\hline K207 & Blackface & G & 2.5 & 0 & 0 &,-- & C \\
\hline K208 & Blackface & G & 2.5 & 0 & 0 &,-- & $C$ \\
\hline K213 & Blackface & G & 2.5 & 0 & 0 &,-- & $C$ \\
\hline K224 & Blackface & G & 2.5 & 0 & 0 &,-- & $C$ \\
\hline K227 & Blackface & G & 2.5 & 0 & 0 &,-- & $C$ \\
\hline K229 & Blackface & G & 2.5 & 0 & 0 &,-- & $C$ \\
\hline
\end{tabular}

a Source farms.

b SGI (Severity of Granulomatous Inflammation) grading: based on total number of epithelioid macrophages and leukocyte distribution patterns of the terminal ileum [46].

c AFB (Acid Fast Bacteria) — grading: grades 0-2 were defined as paucibacillary; grades 3-4 were defined as multibacillary observed in terminal ileum tissue.

d IS900 PCR result using each of the two primer sets.

e Diagnosis: based on histopathological observations.

ND-1000 spectrophotometry and Agilent 2200 TapeStation system; all had an RNA Integrity Number of $>7.4$. cDNA was synthesised from $1 \mu \mathrm{g}$ RNA using SuperScript $^{\mathrm{TM}}$ II RT with RNaseOUT (Invitrogen) and oligo$\mathrm{dT}_{(15)}$ primer (Promega, UK), in a $20 \mu \mathrm{L}$ final volume. Quantitative real-time RT-PCR (RT-qPCR) was performed in $15 \mu \mathrm{L}$ volumes containing $7.5 \mu \mathrm{L}$ FastStart Universal SYBR Green Master (Rox) $2 \times$ concentration (Roche), $2 \mu \mathrm{l}$ template cDNA (diluted 1/10-1/40), $1 \mu \mathrm{L}$ dNTPs $(10 \mathrm{mM})$ primers and nuclease-free water; primer sequences, Tm and product sizes (Additional file 1) have been published [31]. Reactions were prepared using a CAS $-1200^{\mathrm{TM}}$ robot and performed on a RotorGene Q (Qiagen). All reactions had an efficiency $>95 \%$ and $R^{2}>0.98$; PCR amplicons were sequenced to confirm specificity. Three biological (RT) replicates per animal were assayed, each in duplicate and duplicate no-template controls were included in all runs.

Relative gene expression levels were calculated in GenEx 5 (MultiD Analyses AB, Sweden) using the comparative $2-(\Delta \Delta \mathrm{Cq})$ method and normalized to the geometric mean of YWHAZ and SDHA. Fold changes were calculated from $\triangle \mathrm{Cq}$ values using GenEx. The difference between the group means for each gene was analysed using Graphpad Prism 6 by one-way ANOVA to determine overall significance, with Tukey's multiple comparison test within ANOVA to determine significance between groups.

\section{Results}

Paratuberculosis-diseased and control sheep

The pathological characteristics of the three groups of animals is shown in Table 1. Representative haematoxylin and eosin and Ziehl-Neelsen histopathology of the lymph node is shown in Additional file 2. All infected animals were $I S 900$ positive with both primer sets; all amplicons were sequenced and confirmed to be $100 \%$ identical with Mycobacterium avium subsp. paratuberculosis insertion sequence IS900 sequence (accession no. S74401.1). All uninfected control sheep were negative for IS900 PCR using both primer sets under all four PCR conditions. 


\section{Master regulator transcription variants}

Cloning and sequencing of transcription factor transcripts from abomasal lymph node identified two variants of GATA3, two variants of $R O R C 2$, five variants of $R O R A$ and a single $T B X 21$ transcript [31]. In summary (Additional file 3), the two GATA3 variants include the full length GATA3 (LN848231) and GATA3v1 (LN848232) that has a single codon deletion at the $5^{\prime}$ end of exon 3 (g.806_808delGAA) that encodes glutamic acid at position 260 . The two $R O R C 2$ variants include a full length transcript (RORC2, LN848233) and a truncated transcript RORC2v1 (LN848234) with a 36 bp deletion (g.1237_1272del), which encodes GKYGGVELFRAL at position 359-370. The five RORA variants (LN848235LN848239) have different $5^{\prime}$ sequences, RORAv1, v2, v3 and $v 5$ have different translation start sites, and RORAv2 and $v 4$ have identical start sites. All five variants have the same ligand-binding domain but RORAv2 and $v 4$ do not encode the DNA-binding domain. RORAv1, v3 and $v 5$ encode different $\mathrm{NH}_{2}$ sequences upstream of the DNAbinding domain.

\section{TBX21 and GATA3 expression}

Relative RT-qPCR analysis of the master regulator transcription factors that control Th1 and Th2 $\mathrm{T}$ cell differentiation showed that there were overall significant differences in the expression of TBX21 $(P=0.003)$ and GATA3 $(P=0.046)$ but not the variant GATA3v1 $(P=0.32)$ (Table 2). Comparison between the groups (Figure 1) showed that TBX21 was significantly increased in paucibacillary sheep, resulting in a 2.6 fold change in the $P$ vs. $C$ comparison $(P \leq 0.01)$ and a -1.88 fold change in the $\mathrm{M}$ vs. $P$ comparison $(p \leq 0.05)$. Similar analysis for GATA3 showed a significant -2.08 fold change $(P \leq 0.05)$ in the $M$ vs. $P$ comparison, but no significant differences were measured in the $M$ vs. $C(-1.6$ fold) and $P$ vs. C (1.2 fold) comparisons. There were no significant differences between the groups with GATA3v1 (Figure 1C).

\section{RORC2 expression}

Quantification of two RORC2 variants showed overall significant differences (Table 2) for both the full length transcript $(R O R C 2, P=0.0004)$ and the truncated transcript (RORC2v1, $P=0.0026)$. Both transcripts behaved similarly in the between-group comparisons. RORC2 and RORC2v1 (Figure 2) showed significant 2.4 and 3.09 (both $P \leq 0.05$ ) fold changes respectively in the $M$ vs. $C$ comparison; and significant $3.48(P \leq 0.001)$ and 3.49 $(P \leq 0.01)$ fold changes respectively in the $P$ vs. $C$ comparison. Neither was significantly different in the M vs. $P$ comparison.

\section{RORA expression}

Quantification of the $R O R A$ transcript variants could be performed only for RORAv1, RORAv4 and RORAv5 because expression levels of RORAv2 and RORAv3 were too low for accurate measurements (detected at $>30$ cycles, below the linear part of the titration curve). Overall significant differences (Table 2) were identified for both RORAv1 $(P=0.0053)$ and RORAv4 $(P=0.0002)$. RORAv5 was marginally insignificant $(P=0.07)$. Comparison between the groups (Figure 3) showed that RORAv1 was significantly increased in lymph nodes from paucibacillary animals ( $P$ vs. $C ; 2.49$ fold, $P \leq 0.01$ and (M vs. $P ;-1.9$ fold, $P \leq 0.05)$. RORAv 4 was significantly increased in both the $\bar{M}$ vs. $C(2.78$ fold, $P \leq 0.001)$ and $P$ vs. C comparisons (2.89 fold, $P \leq 0.001$ ), but was equally expressed in the multi- and paucibacillary groups $(-1.04$ fold). $R O R V v 5$ was not significantly different in any of the three comparisons, although it was increased by 2.67 fold in the $P$ vs. C comparison.

Table 2 Relative expression of transcription factors within the ICLN

\begin{tabular}{|c|c|c|c|c|c|c|c|}
\hline \multirow[t]{2}{*}{ Gene } & \multirow[t]{2}{*}{ ANOVA $P$ value } & \multicolumn{2}{|c|}{ Multi vs. control } & \multicolumn{2}{|c|}{ Pauci vs. control } & \multicolumn{2}{|c|}{ Multi vs. pauci } \\
\hline & & $\mathrm{FC}^{\mathrm{a}}$ & $P$ value & FC & $P$ value & FC & $P$ value \\
\hline TBX21 & 0.003 & 1.38 & ns & 2.6 & $\leq 0.01$ & -1.88 & $\leq 0.05$ \\
\hline GATA3 & 0.046 & -1.6 & ns & 1.2 & ns & -2.08 & $\leq 0.05$ \\
\hline GATA3v1 & 0.32 & -1.5 & ns & -1.25 & ns & -1.2 & ns \\
\hline$R O R C 2$ & 0.0004 & 2.4 & $\leq 0.05$ & 3.48 & $\leq 0.001$ & -1.45 & ns \\
\hline$R O R C 2 v 1$ & 0.0026 & 3.09 & $\leq 0.05$ & 3.49 & $\leq 0.01$ & -1.12 & ns \\
\hline RORAv1 & 0.0053 & 1.2 & ns & 2.49 & $\leq 0.01$ & -1.9 & $\leq 0.05$ \\
\hline RORAv4 & 0.0002 & 2.78 & $\leq 0.001$ & 2.89 & $\leq 0.001$ & -1.04 & ns \\
\hline RORAv5 & 0.07 & 1.8 & ns & 2.67 & ns & -1.47 & ns \\
\hline
\end{tabular}

a Fold change ( $\Delta \Delta$ Cq values).

Italics: $P \leq 0.05$. 


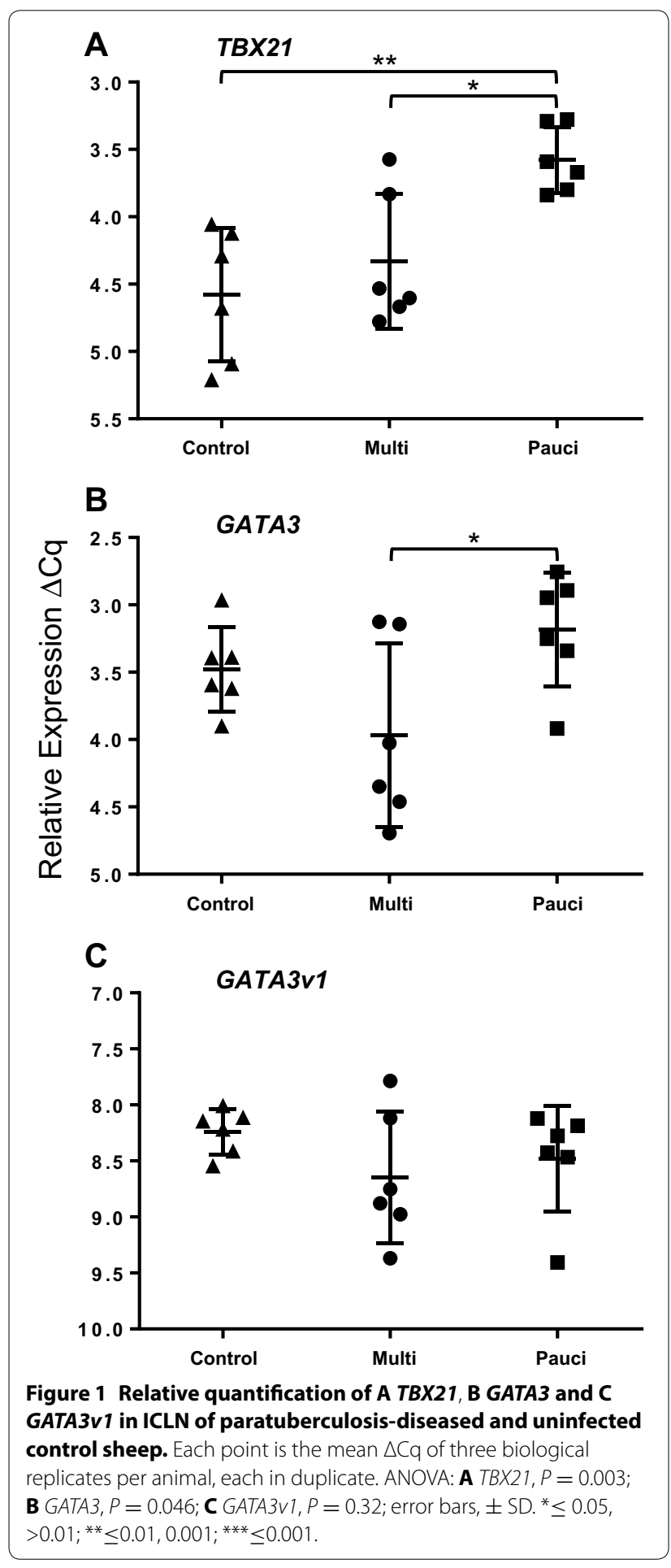

\section{Discussion}

Previous studies investigating cytokine transcripts indicated that sheep paucibacillary disease is strongly associated with Th1/Th17 activation and that multibacillary pathology is linked to a Th2 $\mathrm{T}$ cell response [7, 34, 35].

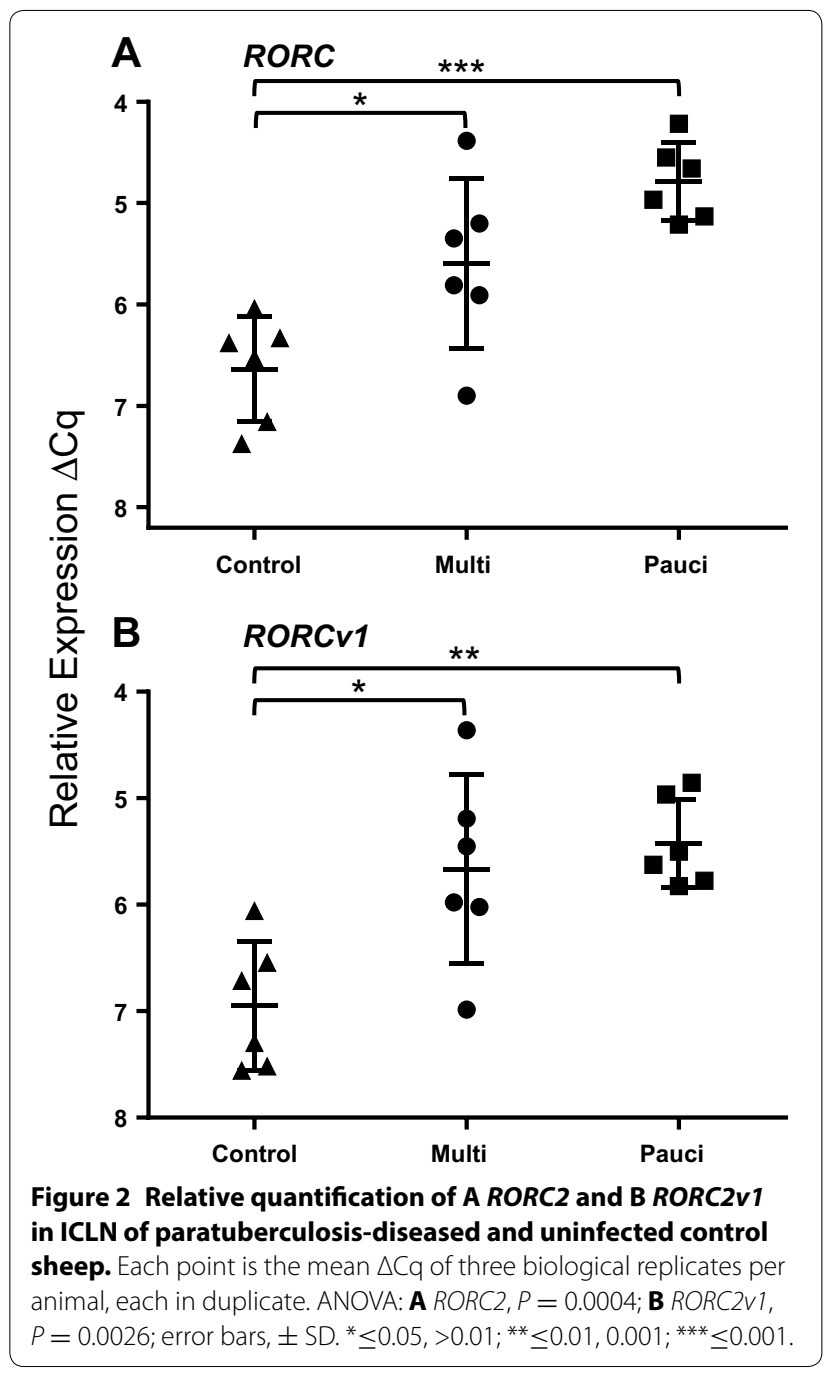

Tbx21, GATA-3, RORyt and ROR $\alpha$ are the master regulator transcription factors responsible for controlling the polarization of these $\mathrm{T}$ cell subsets; and splice variants of these genes have been described in sheep, some of which are differentially expressed in gastrointestinal parasitic disease [31]. This study examined the relationship between the expression of the different variants of these $\mathrm{T}$ cell master regulators and the two paratuberculosis disease pathologies in naturally-infected sheep.

Only one TBX21 transcript has been described in sheep, which showed significant increased expression in ICLN from paucibacillary animals when compared to both uninfected controls ( 2.6 fold, $P \leq 0.01$ ) and multibacillary sheep ( 1.88 fold, $P \leq 0.05)$. These data contrast with measurements made from jejunal lymph nodes in experimentally-infected red deer [36], where there was no differential expression of TBX21, and IFNG levels were increased only in "severe disease" (multibacillary) cases. The difference might be associated with anatomical 


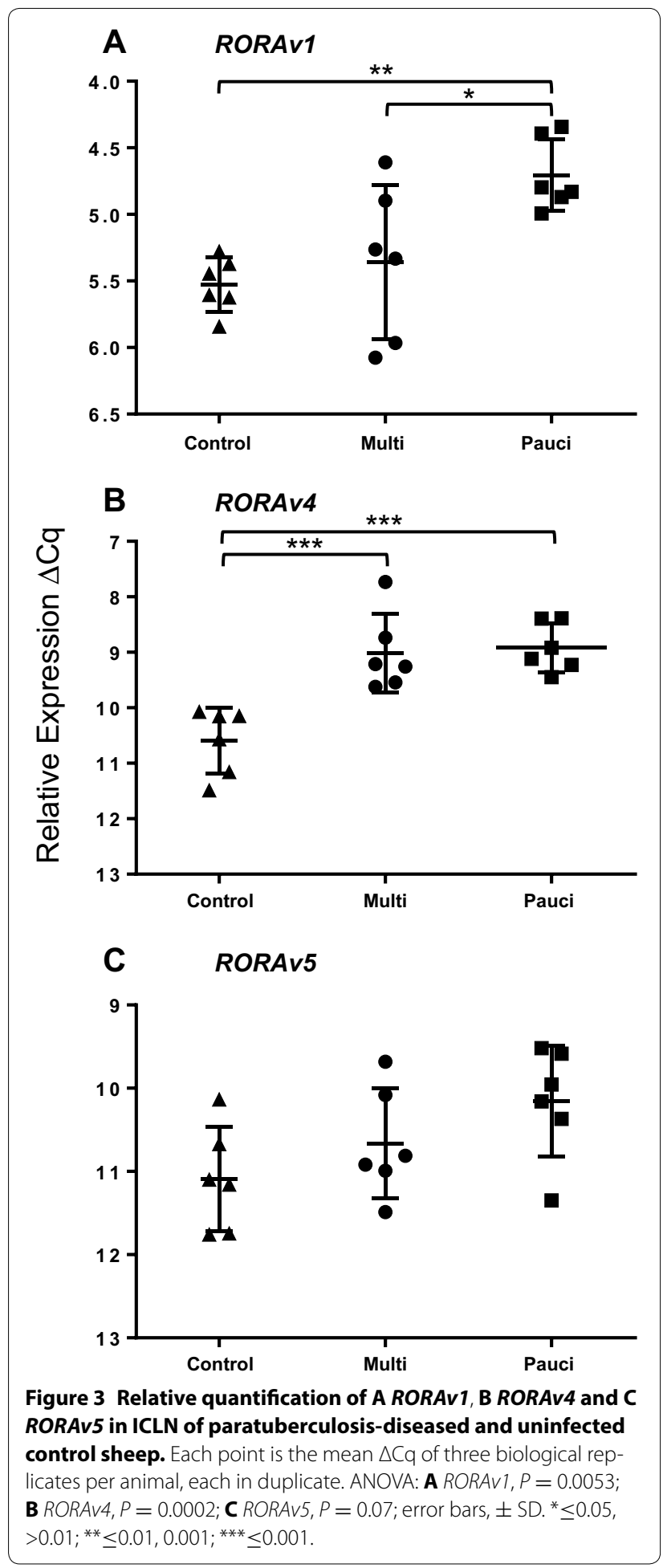

location of the lymph nodes, as Begg et al. [37] showed that responses to infection varied with their position. The immune response to paratuberculosis is greatest at the location of the most severe lesions [37]; the terminal ileum is a major site of the paratuberculosis lesions in sheep [3] and the ICLN is the major immune inductive site for that tissue. Tbx 21 is required for Th1 activation as it induces the expression of IFNy [18]; which is the critical cytokine for controlling intracellular mycobacterial replication [6]. High levels of both TBX21 and IFNG transcripts are seen in human Crohn's disease [38] and TBX21 SNPs are linked with resistance to human pulmonary tuberculosis [39]. In sheep paratuberculosis therefore, high levels of $T B X 21$ expression may explain the increased levels of IFNY $[7,40]$ and the consequent low numbers of MAP in paucibacillary lesions.

The expression of the full length GATA3 variant was significantly increased ( 2.08 fold, $P \leq 0.05)$ in the paucibacillary sheep in comparison to multibacillary animals but was not significantly different in either of the diseased vs. control comparisons. GATA-3 is required for Th2 differentiation as it transactivates the IL4 cassette and promotes the transcription of IL4, IL5 and IL13 [41]; it also inhibits Th1 responses and is repressed during Th1 development [42]. The increased levels of GATA3 transcripts in paucibacillary sheep, with (non-significantly) reduced levels in multibacillary sheep ( -1.6 fold) is similar to that found in red deer with high levels of GATA3 (and IL4) in "minimal disease" (paucibacillary) and reduced expression in "severe disease" [36]; and these authors suggested that Th2 responses act to control immunopathology in infected animals, and that loss of these responses leads to the multibacillary disease state. GATA3v1 expression showed no significant changes in any of the three comparisons. This variant, which is also found in humans, encodes for GATA-3 with a deletion at position 260 (glutamic acid). The deletion is not within the transactivation domains or either of the zinc-finger domains, nor is it associated with the conserved YxKxHxxxRP motif at position 345-354 that seems to control Th2 cytokine production [43]. To date this is the only study that describes any biological difference between full length GATA3 and GATA3v1 in any species.

Full length RORC2 expression was significantly increased in both the $P$ vs. $C$ (3.48 fold, $P \leq 0.001)$ and $M$ vs. $C$ (2.4 fold, $P \leq 0.05$ ) comparisons. RORC $2 v 1$ behaved in an almost identical manner. Increased ROR $\gamma \mathrm{t}$ expression in humans is associated with a range of inflammatory pathologies, including inflammatory bowel disease [44]; and these data imply that ROR $y$ t-mediated Th17 activity is an important aspect of the chronic inflammation seen in both pathological forms of paratuberculosis. However, the 1.45 fold increase of $R O R C 2$ in the $P$ vs. $M$ comparison (whilst not significant) indicates a trend of increased Th17 cell function in the paucibacillary immunopathology in comparison to multibacillary disease. The twelve amino acid deletion encoded by the 
$R O R C 2 v 1$ variant is within the predicted ligand-binding domain [45], which implies a modification in function; a similar RORC2 variant in humans suppresses $I L 17 A$ and IL21 transcription and consequently inhibits Th17 function [29]. However, there is no indication in these studies that the two sheep variants have any different functions.

Only three of the five RORA variants showed measurable levels of expression. RORAv1 was significantly increased in paucibacillary sheep in comparison to both control (2.49 fold, $P \leq 0.01$ ) and multibacillary sheep (1.9 fold, $P \leq 0.05)$; and RORAv4 was increased in both the $\mathrm{M}$ vs. $C$ (2.78 fold, $P \leq 0.001)$ and $P$ vs. $C$ comparisons $(2.89$ fold, $P \leq 0.001)$. RORAv5 showed no significant differential expression but was 2.67 fold increased in the $P$ vs. C comparison (but not significant). The biological activities of ROR $\alpha$ are mediated by both the ligand-binding and DNA-binding domains [30]. In addition, the amino terminal A and B domains play important roles in intracellular localization, binding specificity and cell tropism. RORAv1 and RORAv5 possesses both ligand- and DNAbinding domains but different $\mathrm{A}$ and $\mathrm{B}$ domains [31]; RORAv4, which encodes the same protein as RORAv2, possesses the conserved ligand-binding domain but lacks the A, B and DNA-binding domains.

Optimal Th17 differentiation requires the co-expression of both RORyt and ROR $\alpha$ [21] and the significantly high levels of RORAv1 in paucibacillary (in comparison to both multibacillary and control sheep) further emphasises an important role for Th17 activation in paucibacillary (tuberculoid) pathology. It is possible that RORAv4, which is found in high levels in both paucibacillary and multibacillary sheep, could compete with RORAv1 for ligand binding and inhibit its function, most effectively in those animals with lower levels of RORAv1 (i.e. multibacillary), with consequent reduction in Th17 activation. This is similar to the differential expression patterns of RORAv2 and RORAv5 seen in parasitic disease pathologies [31].

In conclusion, this study measures the expression of the transcript variants of the master regulator transcription factors that control Th1, Th2 and Th17 T cell differentiation, in sheep with defined paucibacillary and multibacillary paratuberculosis pathology. Relatively low levels of GATA3 in multibacillary animals confirms the data from red deer, but does not confirm that multibacillary (lepromatous) paratuberculosis is primarily caused by Th2 activation. High levels of expression of $T B X 21$, $R O R C 2$ and RORC2v1 highlights the role of both Th1 and Th17 in controlling bacterial replication in paucibacillary disease, and increased expression of RORAv1 emphasises that ROR $\alpha$ plays an important part in Th17 development in this disease. The differentiation between paucibacillary and multibacillary pathology might also concern RORAv4, which may inhibit Th17 activation in multibacillary disease and further contribute to $\mathrm{T}$ cell dysfunction.

\section{Additional files}

Additional file 1: Primer sets for RT-qPCR. The primer sequences, their $\operatorname{Tm}\left({ }^{\circ} \mathrm{C}\right)$ and PCR product sizes used for RT-qPCR.

Additional file 2: Histopathology of lymph node of diseased animals. Haematoxylin and eosin (H\&E) and Ziehl-Neelsen (ZN) histopathology of lymph node from multibacillary (SH139) and paucibacillary (SH155) diseased animals. Inserts are terminal ileum from the same animals. All images are $\times 10$ magnification.

Additional file 3: 5' nucleotide sequences of Ovis aries $\mathrm{T}$ cell transcription factor variants. A. GATA3 (LN848231 and LN848232). B. RORC2 (LN848233 and LN848234. C. RORA (LN848235, LN848236, LN848237, LN848238, LN848239).

\section{Competing interests}

The authors declare that they have no competing interests.

\section{Authors' contributions}

LN performed the experiments, including development of the RT-qPCR assays, and analyzed the data; HW identified the gene variants and designed the primers; AG performed the IS900 PCR; CW supplied the diseased animals and performed the post mortems; RD and JH were the students' supervisors and conceived the project. JH is the grant holder and drafted the manuscript. All authors read and approved the final manuscript.

\section{Acknowledgements}

We thank Dr Francesca Chianini, The Moredun Institute for pathological diagnosis of diseased animals, MRI Bioservices and Joan Docherty (The Marshall Building) for animal husbandry of infected and control animals and Joyce McLuckie for bacterial culture. This project was funded by the Biotechnology and Biological Sciences Research Council (BBSRC) Institute Strategic Programme Grant to The Roslin Institute. LN was a BBSRC postgraduate student funded by the BBSRC Doctoral Training Grant BB/D526245/1. HW is a BBSRC Industrial CASE scholar, sponsored by Sheep Improved Genetics Ltd and financially supported by BBSRC and AHDB Beef and Lamb (Grant BB/J012653/1). The funders had no role in study design, data collection and interpretation, or the decision to submit the work for publication.

\section{Author details}

${ }^{1}$ The Roslin Institute \& R(D)SVS, University of Edinburgh, Easter Bush, Midlothian EH25 9RG, UK. ${ }^{2}$ Moredun Research Institute, International Research Centre, Pentlands Science Park, Penicuik, Midlothian EH26 OPZ, UK.

Received: 13 May 2016 Accepted: 27 July 2016

Published online: 17 August 2016

References

1. Harris N, Barletta R (2001) Mycobacterium avium subsp. paratuberculosis in Veterinary Medicine. Clin Microbiol Rev 14:489-512

2. Dye C, Williams BG (2010) The population dynamics and control of tuberculosis. Science 328:856-861

3. Clarke C (1997) The pathology and pathogenesis of paratuberculosis in ruminants and other species. J Comp Pathol 116:217-261

4. Gillan S, O'Brien R, Hughes AD, Griffin JFT (2010) Identification of immune parameters to differentiate disease states among sheep infected with Mycobacterium avium subsp. paratuberculosis. Clin Vaccine Immunol 17:108-117

5. Casanova J-L, Abel L (2002) Genetic dissection of immunity to mycobacteria: the human model. Annu Rev Immunol 20:581-620 
6. O'Garra A, Redford PS, McNab FW, Bloom Cl, Wilkinson RJ, Berry MPR (2013) The immune response in tuberculosis. Annu Rev Immunol 31:475-527

7. Smeed JA, Watkins CA, Rhind SM, Hopkins J (2007) Differential cytokine gene expression profiles in the three pathological forms of sheep paratuberculosis. BMC Vet Res 3:18

8. Whittington RJ, Begg DJ, de Silva K, Plain KM, Purdie AC (2012) Comparative immunological and microbiological aspects of paratuberculosis as a model mycobacterial infection. Vet Immunol Immunopathol 148:29-47

9. Burrells C, Clarke CJ, Colston A, Kay JA, Porter J, Little D, Sharp JM (1998) A study of immunological responses of sheep clinically-affected with paratuberculosis (Johne's disease): the relationship of blood, mesenteric lymph node and intestinal lymphocyte responses to gross and microscopic pathology. Vet Immunol Immunopathol 66:343-358

10. Allen AJ, Park KT, Barrington GM, Lahmers KK, Abdellrazeq GS, Rihan HM, Sreevatsan S, Davies C, Hamilton MJ, Davis WC (2011) Experimental infection of a bovine model with human isolates of Mycobacterium avium subsp. paratuberculosis. Vet Immunol Immunopathol 141:258-266

11. Begg D, de Silva K, Carter N, Plain K, Purdie A, Whittington R (2011) Does a Th1 over Th2 dominancy really exist in the early stages of Mycobacterium avium subspecies paratuberculosis infections? Immunobiology 216:840-846

12. Roussey JA, Oliveira LJ, Langohr IM, Sledge DG, Coussens PM (2016) Regulatory T cells and immune profiling in Johne's disease lesions. Vet Immunol Immunopathol. doi:10.1016/j.vetimm.2016.03.008

13. Roussey JA, Steibel J, Coussens PM (2014) Regulatory T cell activity and signs of T cell unresponsiveness in bovine paratuberculosis. Front Vet Sci $1: 20$

14. Leite FL, Eslabao LB, Pesch B, Bannantine JP, Reinhardt TA, Stabel JR (2015) ZAP-70, CTLA-4 and proximal T cell receptor signaling in cows infected with Mycobacterium avium subsp. paratuberculosis. Vet Immunol Immunopathol 167:15-21

15. Okagawa T, Konnai S, Nishimori A, Ikebuchi R, Mizorogi S, Nagata R, Kawaji S, Tanaka S, Kagawa Y, Murata S, Mori Y, Ohashi K (2016) Bovine immunoinhibitory receptors contribute to suppression of Mycobacterium avium subsp. paratuberculosis-specific T-cell responses. Infect Immun 84:77-89

16. van de Vosse E, Hoeve MA, Ottenhoff THM (2004) Human genetics of intracellular infectious diseases: molecular and cellular immunity against mycobacteria and salmonellae. Lancet Infect Dis 4:739-749

17. Saini C, Ramesh V, Nath I (2013) CD4+ Th17 cells discriminate clinical types and constitute a third subset of non Th1, Non Th2 T cells in human leprosy. PLoS Negl Trop Dis 7:e2338

18. Zhu J, Yamane H, Paul WE (2010) Differentiation of effector CD4T cell populations. Annu Rev Immunol 28:445-489

19. Hwang ES, Szabo SJ, Schwartzberg PL, Glimcher LH (2005) T helper cell fate specified by kinase-mediated interaction of T-bet with GATA-3. Science 307:430-433

20. Zhu JF, Yamane H, Cote-Sierra J, Guo LY, Paul WE (2006) GATA-3 promotes Th2 responses through three different mechanisms: induction of Th2 cytokine production, selective growth of Th2 cells and inhibition of Th1 cell-specific factors. Cell Res 16:3-10

21. Yang XO, Pappu BP, Nurieva R, Akimzhanov A, Kang HS, Chung Y, Ma L, Shah B, Panopoulos AD, Schluns KS, Watowich SS, Tian Q, Jetten AM, Dong C (2008) Thelper 17 lineage differentiation is programmed by orphan nuclear receptors RORa and RORY. Immunity 28:29-39

22. Tait Wojno ED, Artis D (2012) Innate lymphoid cells: balancing immunity, inflammation, and tissue repair in the intestine. Cell Host Microbe 12:445-457

23. Lazarevic V, Glimcher LH (2011) T-bet in disease. Nat Immunol 12:597-606

24. Ohtani K, Ohtsuka Y, Ikuse T, Baba Y, Yamakawa Y, Aoyagi Y, Fujii T, Kudo T, Nagata S, Shimizu T (2010) Increased mucosal expression of GATA-3 and STAT-4 in pediatric ulcerative colitis. Pediatr Int 52:584-589

25. Kanai T, Mikami Y, Sujino T, Hisamatsu T, Hibi T (2012) RORyt-dependent IL-17A-producing cells in the pathogenesis of intestinal inflammation. Mucosal Immunol 5:240-247

26. Delerive P, Monte D, Dubois G, Trottein F, Fruchart-Najib J, Mariani J, Fruchart JC, Staels B (2001) The orphan nuclear receptor ROR alpha is a negative regulator of the inflammatory response. EMBO Rep 2:42-48

27. Black DL (2000) Protein diversity from alternative splicing: a challenge for bioinformatics and post-genome biology. Cell 103:367-370
28. Pykalainen M, Kinos R, Valkonen S, Rydman P, Kilpelalainen M, Laitinen LA, Karjalainen J, Nieminen M, Hurme M, Kere J, Laitinen T, Lahesmaa R (2005) Association analysis of common variants of STAT6, GATA3, and STAT4 to asthma and high serum IgE phenotypes. J Allergy Clin Immunol 115:80-87

29. Rauen T, Juang YT, Hedrich CM, Kis-Toth K, Tsokos GC (2012) A novel isoform of the orphan receptor RORyt suppresses IL-17 production in human T cells. Genes Immun 13:346-350

30. Giguère V,Tini M, Flock G, Ong E, Evans RM, Otulakowski G (1994) Isoform-specific amino-terminal domains dictate DNA-binding properties of ROR alpha, a novel family of orphan hormone nuclear receptors. Genes Dev 8:538-553

31. Wilkie H, Gossner A, Bishop S, Hopkins J (2016) Variations in T cell transcription factor sequence and expression associated with resistance to the sheep nematode Teladorsagia circumcincta. PLoS One 11:e0149644

32. Eishi Y, Suga M, Ishige I, Kobayashi D, Yamada T, Takemura T, Takizawa T, Koike M, Kudoh S, Costabel U, Guzman J, Rizzato G, Gambacorta M, du Bois R, Nicholson AG, Sharma OP, Ando M (2002) Quantitative analysis of mycobacterial and propionibacterial DNA in lymph nodes of Japanese and European patients with sarcoidosis. J Clin Microbiol 40:198-204

33. Bauerfeind R, Benazzi S, Weiss R, Schliesser T, Willems H, Baljer G (1996) Molecular characterization of Mycobacterium paratuberculosis isolates from sheep, goats, and cattle by hybridization with a DNA probe to insertion element IS900. J Clin Microbiol 34:1617-1621

34. Gossner AG, Venturina VM, Peers A, Watkins CA, Hopkins J (2012) Expression of sheep interleukin 23 (IL23A, alpha subunit p19) in two distinct gastrointestinal diseases. Vet Immunol Immunopathol 150:118-122

35. Nicol L, Gossner A, Watkins C, Chianini F, Dalziel R, Hopkins J (2016) Variations in IL-23 and IL-25 receptor gene structure, sequence and expression associated with the two disease forms of sheep paratuberculosis. Vet Res 47:27

36. Robinson MW, O'Brien R, Mackintosh CG, Clark RG, Griffin JFT (2011) Immunoregulatory cytokines are associated with protection from immunopathology following Mycobacterium avium subspecies paratuberculosis infection in red deer. Infect Immun 79:2089-2097

37. Begg DJ, O'Brien R, Mackintosh CG, Griffin JT (2005) Experimental infection model for Johne's disease in sheep. Infect Immun 73:5603-5611

38. Matsuoka K, Inoue N, Sato T, Okamoto S, Hisamatsu T, Kishi Y, Sakuraba A, Hitotsumatsu O, Ogata H, Koganei K, Fukushima T, Kanai T, Watanabe M, Ishii H, Hibi T (2004) T-bet upregulation and subsequent interleukin 12 stimulation are essential for induction of Th1 mediated immunopathology in Crohn's disease. Gut 53:1303-1308

39. Sanchez D, Lefebvre C, Garcia LF, Barrera LF (2013) Variants in the IFNg transcription factor genes TBET, STAT1, STAT4, and HLX and the risk of pulmonary tuberculosis in a Colombian population: a case-control study. Biomedica 33:259-267

40. Coussens PM, Verman N, Coussens MA, Elftman MD, McNulty AM (2004) Cytokine gene expression in peripheral blood mononuclear cells and tissues of cattle infected with Mycobacterium avium subsp. paratuberculosis: evidence for an inherent proinflammatory gene expression pattern. Infect Immun 72:1409-1422

41. Ho IC, Tai T-S, Pai S-Y (2009) GATA3 and the T-cell lineage: essential functions before and after T-helper-2-cell differentiation. Nat Rev Immunol 9:125-135

42. Yagi R, Zhu J, Paul WE (2011) An updated view on transcription factor GATA3-mediated regulation of Th1 and Th2 cell differentiation. Int Immunol 23:415-420

43. Shinnakasu R, Yamashita M, Shinoda K, Endo Y, Hosokawa H, Hasegawa A, Ikemizu S, Nakayama T (2006) Critical YxKxHxxxRP motif in the C-terminal region of GATA3 for its DNA binding and function. J Immunol 177:5801-5810

44. Korn T, Bettelli E, Oukka M, Kuchroo VK (2009) IL-17 and Th17 Cells. Annu Rev Immunol 27:485-517

45. Medvedev A, Chistokhina A, Hirose T, Jetten AM (1997) Genomic structure and chromosomal mapping of the nuclear orphan receptor ROR gamma (RORC) gene. Genomics 46:93-102

46. Dennis MM, Reddacliff $L A$, Whittington RJ (2011) Longitudinal study of clinicopathological features of Johne's disease in sheep naturally exposed to Mycobacterium avium subspecies paratuberculosis. Vet Pathol 48:565-575 